\title{
DETERMINAÇÃO DE PADRÕES DE CHUVA CRÍTICA PARA OCORRÊNCIA DE ALAGAMENTOS EM CURITIBA-PR UTILIZANDO REDE NEURAL ARTIFICIAL SOM (Self Organizing Map)
}

\author{
Marciel Lohmann - marciel_lohmann@yahoo.com.br \\ Doutor. Sistema Meteorológico do Paraná (SIMEPAR) Curitiba/PR \\ Leonardo José Cordeiro Santos - santos.ufpr@gmail.com \\ Doutor. Professor. Universidade Federal do Paraná - Curitiba/PR
}

\begin{abstract}
RESUMO: Alagamentos e inundações são fenômenos recorrentes principalmente nos meses de verão, cujas consequências acarretam diversos transtornos e perdas materiais para a população afetada. O presente artigo propõe determinar por meio de inteligência artificial os padrões de chuva crítica em Curitiba, procurando estabelecer a relação entre chuva e alagamentos para o município, utilizando como base a integração de informações hidrometeorológicas. Para a construção do modelo foi utilizado os dados de precipitação estimada a partir da integração das informações provenientes de radar meteorológico, satélite e pluviômetros, utilizando o método de Análise Objetiva Estatística (ANOBES). A partir dos dados de estimativas de precipitação foi calculada a chuva média acumulada de 6 em 6 horas, utilizando-se do método de Thiessen. Os resultados gerados por meio da rede neural SOM (Mapas Auto Organizáveis), definiram quais os principais padrões de chuva responsáveis por deflagrar os alagamentos em Curitiba, sendo identificados 2 padrões principais.
\end{abstract}

PALAVRAS-CHAVE: Alagamentos; Rede Neural, Padrões de Chuva;

DETERMINATION OF CRITICAL RAIN STANDARDS FOR FLOODING OCCURRENCE IN CURITIBA-PR NETWORK USING ARTIFICIAL NEURAL SOM (SELF ORGANIZING MAP)

ABSTRACT: Floods are recurring phenomena especially in the summer months, and the consequences of which generate many disorders and material losses to the affected population. This paper proposes to determine through artificial intelligence the critical rainfall patterns in Curitiba, to establish the relationship between rain and flooding to the city, using as a basis the integration of hydrometeorological information. For the construction of the model were used rainfall data estimated from the integration of meteorological radar, satellite and rain gauges data, using the analysis for statistical purposes (ANOBES) method. Rainfall estimates were used to calculate cumulative average rain of 6 hours in a basis of 4 days, using the method of Thiessen. The results generated by the neural network SOM (Self Organizing Maps), which defined the main rainfall patterns responsible for triggering the flooding in Curitiba, identified two main patterns.

KEY-WORDS: Flooding, Neural Networks, Rain Patterns

\section{INTRODUÇÃO}

Frequentemente são noticiadas informações sobre alagamentos e inundações em Curitiba, principalmente nas porções da grande planície aluvial do rio Iguaçu, bem como em algumas bacias que deságuam no Iguaçu, mas que tem praticamente toda sua área integrada na RMC (Região Metropolitana de Curitiba), como no caso da bacia hidrográfica do rio Belém e do rio Atuba.

É de consenso por parte de diversos autores, que as chuvas de maior interesse são as torrenciais do tipo convectivas, cuja duração não ultrapassa 40 
minutos. Essas chuvas ocorrem em Curitiba e RMC, principalmente entre novembro a março, às vezes acompanhadas de granizo.

Vários trabalhos foram publicados levando em consideração a problemática das inundações em Curitiba e RMC. Dentre eles encontra-se as publicações de Zanela (2005), que analisou as inundações no bairro Cajuru em Curitiba, elaborando um estudo sobre os impactos da urbanização nas inundações que ocorrem no bairro. Fortunato (2006), também falando sobre tal problemática, analisou as inundações na bacia do rio Belém, buscando subsídios para a prevenção e o controle das inundações nas cidades por meio de ações de planejamento e gestão ambiental urbana.

Fortunato (2006), analisando as fontes disponíveis de dados sobre inundações, comenta que a maior parte das informações disponíveis faz referência à inundação que ocorreu no ano de 1983 e 1999. Comenta ainda que a maior parte das informações sobre os eventos é registrada pelos jornais de maior veiculação diária na cidade. Tais relatos também são utilizados por Zanela (2005).

JICA (1995), em um estudo sobre inundações no estado do Paraná, identificou cinco áreas críticas sujeitas a inundações na Bacia do rio Iguaçu. Dentre essas cinco encontra-se a Região Metropolitana de Curitiba. Neste estudo, afirmam que as inundações ocorrem nas áreas próximas ao rio Iguaçu e seus tributários: rio Atuba, rio Irai, rio Palmital, rio Pequeno, rio Belém, rio Ivo e rio Barigui. Nesta região, ocorreram inundações em 1980, 1981, 1982, 1983, 1988, 1992, 1993 e 1995. No entanto, a maior inundação ocorreu em 1983 contabilizando só em Curitiba cerca de 200.000 vítimas. Esse evento crítico provocou na época uma série de mobilizações e proposições visando solucionar problemas relacionados à drenagem urbana no município.

Fendrich (2000) definiu a precipitação responsável pela inundação em 1999 como representante de um risco hidrológico de tempo de recorrência de 100 anos - considerando o modelo desenvolvido pelo autor para Simulação de Cotas de Enchente na Bacia do rio Belém. Para Fendrich, vários fatores contribuíram para a magnitude desse evento, o qual atingiu marca crítica de 6,2 m registrada no Campus da PUC-PR - Estação Pluviográfica Curitiba Prado Velho, onde o leito normal é de $0,7 \mathrm{~m}$. Dentre esses fatores pode-se citar: maior índice pluviométrico na Estação Prado Velho $(197,5 \mathrm{~mm})$; chuva acumulada entre 01/01/1999 e 20/02/1999, que tornou a capacidade de infiltração da bacia (Formação Guabirotuba) quase nula; áreas impermeabilizadas na bacia, as quais agravaram ainda mais o quadro de infiltração na mesma, implicando em um rápido escoamento superficial em direção aos canais; chuva convectiva intensa com quase duas horas de duração; deslocamento da chuva do sentido Norte para o Sul, acompanhando o relevo da bacia hidrográfica do Belém, ampliando o fluxo de águas do Alto para o Médio e Baixo Belém.

Levando em consideração o exposto, é de suma importância conhecer os principais padrões de chuva que podem ser deflagradores de alagamentos em uma determinada região. Para tanto, há diversas técnicas de reconhecimento de padrões, que utilizam de tecnologias e modelos existentes, já descritos na literatura. Entre elas encontram-se as redes neurais artificiais, as quais aprimoram-se na adequação de processos que satisfaçam as necessidades de novos algoritmos para o tratamento e reconhecimento de dados meteorológicos.

Assim, este trabalho objetivou, utilizando a rede neural artificial SOM (Self Organizing Map), determinar os padrões de chuva crítica para ocorrência de alagamentos em Curitiba (Figura 1). 
Portanto, a área de estudo consiste no município de Curitiba, inserido na Região Metropolitana de Curitiba (RMC) localizado no Primeiro Planalto Paranaense, com altitude média de $934,6 \mathrm{~m}$ acima do nível do mar e caracterizado geomorfologicamente de acordo com Canali e Muratori (1981) como uma bacia de sedimentação, encravada em compartimento intermontano, tendo sua gênese relacionada às superfícies de pediplanação. As declividades predominantes são baixas variando de 0 a $12 \%$, fato que facilitou a expansão urbana da cidade, atualmente com sua maior área impermeabilizada e, tendo como uma das consequências as inundações e alagamentos.

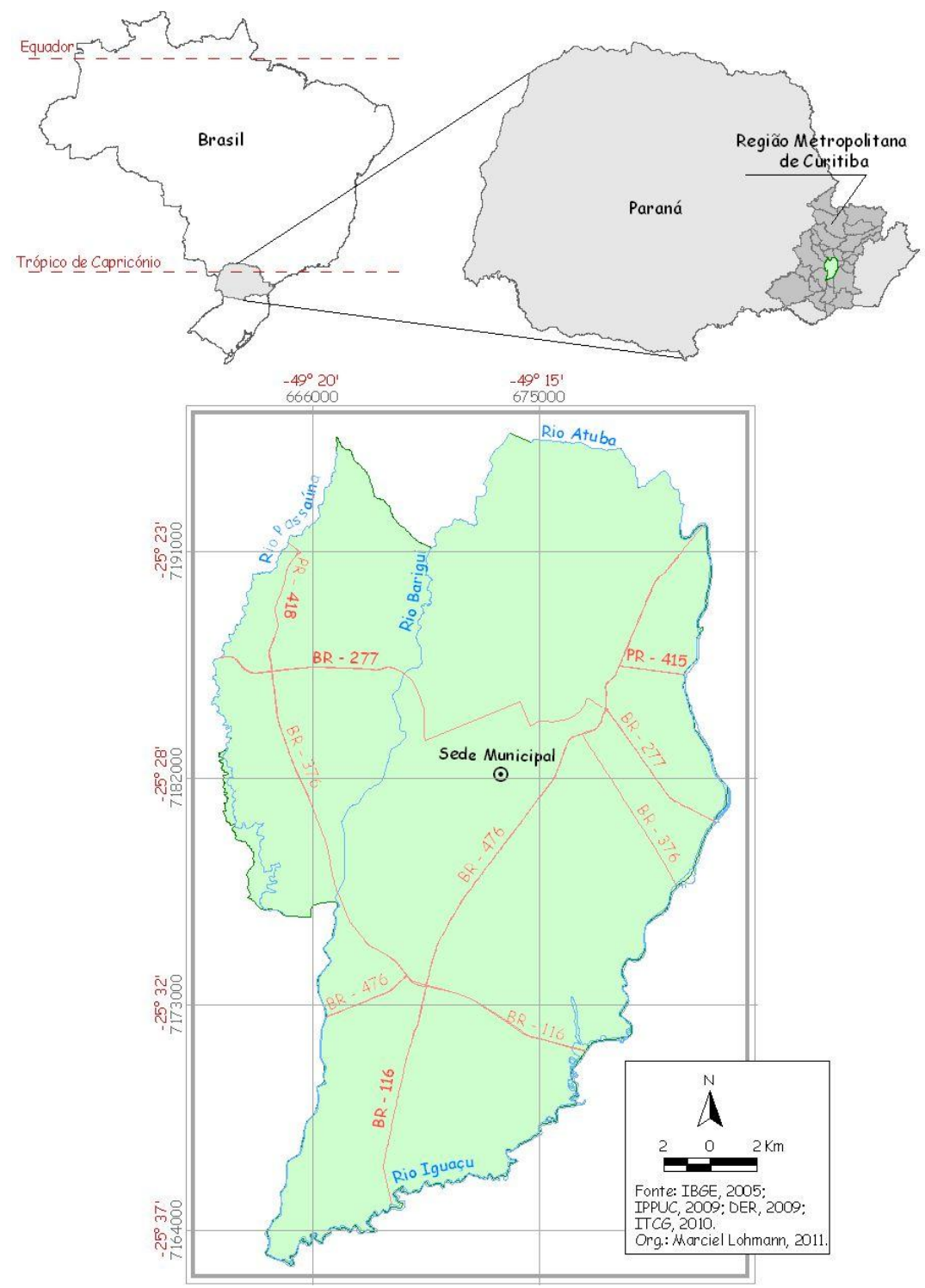

Figura 1 Localização do município de Curitiba 


\section{MATERIAIS E MÉTODOS \\ 2.1 Dados de Chuva}

Este trabalho optou por utilizar como base os dados de chuva estimada a partir da integração das informações provenientes de radar meteorológico, satélite e pluviômetros, utilizando o método de Análise Objetiva Estatística (ANOBES).

De acordo com Calvetti et al (2006), Beneti et al (2002, 2006) e Pereira Filho (2004) é um dos mais eficientes esquemas de interpolação de dados. Este método foi inicialmente desenvolvido em 1963 e posteriormente recomendado pela Organização Meteorológica Mundial (WMO) em 1970, para interpolação de dados hidrometeorológicos. Este método de interpolação (Daley ${ }^{1}$, 1991 apud Calvetti et al 2006), embora simples e dedutível matematicamente, foi pouco aplicado operacionalmente até recentemente, por causa das limitações de processamento computacional. Com o advento de computadores com grande capacidade de processamento e armazenamento, e a um custo baixo, estas restrições ao uso do método ANOBES foram superadas.

O método ANOBES foi adaptado por Pereira Filho (1996) para ser utilizado com dados da rede de radares dos Estados Unidos. Posteriormente, este método foi aplicado com sucesso na reanálise de chuva acumulada horária da rede NEXRAD sobre uma bacia hidrográfica do Bureau of Reclamation em Oklahoma (Pereira Filho et al., 1998) e atualmente está sendo aplicado e já implementado no SIMEPAR (Beneti et al.,2006, Calvetti et al., 2006).

A equação de Análise Objetiva Estatística (ANOBES) é dada por:

$$
P_{a}\left(x_{r}\right)=P_{b}\left(x_{r}\right)+\sum_{n-1}^{N} W_{n}\left[P_{o}\left(x_{n}\right)-P_{b}\left(x_{n}\right)\right]
$$

onde,

Pa (xr ) é a precipitação analisada;

$P b(x r)$ é a precipitação estimada pelo radar ("background");

$P o(x n)$ é a precipitação medida pelo pluviômetro ("observação");

$P b(x n)$ é a precipitação estimada pelo radar no pluviômetro;

$W n$ é o peso a posteriori a ser determinado pela configuração de dados da rede;

$\mathrm{N}$ é o número total de pluviômetros;

$X r$ e $x n$ são as respectivas posições dos pontos de grade do radar e dos pluviômetros.

Para derivar os pesos, assume-se que os erros de observação e a precipitação estimada pelo radar ("background") não têm correlação e não tenham viés. A variância esperada do erro da análise, derivada a partir da equação descrita abaixo, é minimizada em relação aos pesos $W n$. A precipitação integrada é derivada da soma das estimativas obtidas pela análise objetiva estatística dividida pela somatória do quadrado das diferenças de cada campo analisado.

Onde

$$
P_{E s t}\left(x_{i}, y_{i}\right)=\frac{P_{R a d}\left(x_{i}, y_{i}\right) \times E_{R a d}^{-2}\left(x_{i}, y_{i}\right)+P_{S a t}\left(x_{i}, y_{i}\right) \times E_{S a t}^{-2}\left(x_{i}, y_{i}\right)}{E_{R a d}^{-2}\left(x_{i}, y_{i}\right)+E_{S a t}^{-2}\left(x_{i}, y_{i}\right)}
$$

\footnotetext{
${ }^{1}$ DALEY, R. Atmospheric Data Analysis. Cambridge University Press. 1991, 457pp.
} 


$$
\begin{aligned}
E_{\text {rad }}\left(x_{i}, y_{i}\right) & =\left(P_{\text {Rad }}\left(x_{i}, y_{i}\right)-P_{\text {obs }}\left(x_{i}, y_{i}\right)\right) \\
E_{\text {Sat }}\left(x_{i}, y_{i}\right) & =\left(P_{\text {Sat }}\left(x_{i}, y_{i}\right)-P_{\text {obs }}\left(x_{i}, y_{i}\right)\right)
\end{aligned}
$$

Assim a integração é ponderada pelas diferenças entre as estimativas de precipitação por radar e satélite e a precipitação medida na rede de pluviômetros. Desta forma, pretende-se obter o padrão espacial das medições por sensoriamento remoto e ponderá-la pela melhor medição volumétrica da intensidade de chuva obtida pela rede de pluviômetros.

Testes utilizando esta técnica foram feitos por Calvetti et al (2007) e Beneti et al (2006), mostrando que a integração das informações torna-se importante não apenas para a análise de sistemas isolados de precipitação, mas também para sistemas frontais fornecendo estimativas mais apropriadas para estudos hidrológicos em bacias hidrográficas. Calvetti et al (opcit), comenta que janeiro é um mês de muitos eventos rápidos de chuva e de intensidade forte a extrema (acima de $50 \mathrm{~mm}$ ). Não raras vezes não é possível identificar tais fenômenos devido a variação espacial e temporal das chuvas. Mesmo assim, a integração das informações proporcionou o melhor campo de precipitação utilizando as melhores características dos sistemas de medição.

Para este trabalho, foram compilados os dados de estimativas de precipitação horária de janeiro de 2005 a dezembro de 2010. Tais dados estavam disponíveis em pontos de grade de 4x4kmpara o estado do Paraná. Foram selecionados apenas os pontos que estavam inseridos nas bacias que drenam para a bacia do rio Iguaçu na RMC (Região Metropolitana de Curitiba). Foi calculada a chuva média utilizando-se o método de Thiessen que considera que cada estação possui um peso proporcional a sua área de influência sobre a bacia. A equação demonstra a formulação matemática deste método, onde $\mathrm{P}$ é o valor de precipitação médio, $p_{i}$ é a precipitação no posto $i$, e $\delta i$ é seu respectivo peso, e $N$ é o número de postos empregados no cálculo.

$$
\mathrm{P}=\sum_{\mathrm{i}=1}^{\mathrm{N}} \delta_{\mathrm{i}} \mathrm{p}_{\mathrm{i}}
$$

O somatório dos pesos que exercem influência em uma dada região deve ser sempre igual a 1 , e o mesmo é calculado pela fração de sua área de influencia sobre a área da região.

Com os dados de chuva calculados para cada bacia e com o intuito de identificar qual a influência de dias anteriores ao que ocorreu o alagamento, convencionou-se utilizar o dia da ocorrência e três dias anteriores a este, por entender que a ocorrência de alagamentos é dinâmica, ou seja, podem ocorrer com chuvas torrenciais ou ainda ter influência de chuvas ocorridas em dias anteriores. Para tanto, foi calculada a chuva acumulada de 6 em 6 horas obtendo-se 16 valores.

\subsection{Rede Neural Artificial SOM (Self Organizing Map)}

Como todas as redes neurais, as de Kohonen são formadas por um conjunto de elementos simples, chamados neurônios, organizados em estruturas mais complexas, que funcionam em conjunto: a rede.

Cada neurônio é uma unidade de processamento que recebe estímulos (de fora do sistema ou de outros neurônios), e produz uma resposta (para outros neurônios ou para fora do sistema). Tal como os neurônios do cérebro, os das redes neurais são interligados entre si por ramificações através das 
quais os estímulos são propagados. O processo de aprendizado consiste em reforçar as ligações que levam o sistema a produzir respostas mais eficientes.

Os dados de entrada da rede foram constituídos pelas séries de chuva acumulada de 6 em 6 horas para 4 dias, gerando portanto, 16 valores consecutivos de chuva (16 dimensões de chuva acumulada), sendo que o primeiro valor refere-se a chuva acumulada de $6 \mathrm{~h}$ no início do $3^{\circ}$ dia anterior ao da ocorrência do alagamento e assim sucessivamente até o último valor que refere-se a chuva acumulada das 18 até as $24 \mathrm{~h}$ do dia da ocorrência do alagamento. A última coluna da tabela possui valor 0 (zero) ou 1 (um). Esta coluna tornou-se necessária em função da rede trabalhar com variáveis binárias comparando a probabilidade de um alagamento ocorrer (1) com a probabilidade de ele não ocorrer (0). A Tabela 1 mostra o exemplo de arquivo construído que serviu de base para entrada no SOM.

Tabela 1 - Exemplo de tabela construída que serviu de base para entrada no SOM

\begin{tabular}{|c|c|c|c|c|c|c|c|c|c|c|c|}
\hline Ano & Mês & Dia & $6 \mid 3$ & $12 \mid 3$ & $18 \mid 3$ & .... & $6 \mid 0$ & $12 \mid 0$ & $18 \mid 0$ & $24 \mid 0$ & Oc. \\
\hline 2005 & 1 & 5 & 0 & 0 & 0 & $\ldots$ & 0,91 & 0,01 & 7,08 & 1,03 & 1 \\
\hline 2005 & 1 & 6 & 0 & 0 & 1,62 & $\ldots$ & 0 & 0 & 6,52 & 1,5 & 0 \\
\hline 2005 & 1 & 7 & 10,17 & 1,64 & 3,96 & $\ldots$ & 1,25 & 0 & 0,57 & 0,18 & 1 \\
\hline
\end{tabular}

Para um determinado modelo preditivo, existem basicamente duas fases que devem ser seguidas. A primeira de "Calibração" e a segunda de "Verificação". A calibração tem por finalidade promover ajustes de alguns parâmetros do modelo para que os resultados simulados tenham comportamento semelhante aos reais ou experimentais. Já a verificação, considerando que modelos são construídos a partir de uma série de pressupostos e simplificações sobre o comportamento do sistema real, consiste em avaliar se esses pressupostos e simplificações foram corretamente implementados no modelo computacional. A partir disso pode-se então, calcular a acurácia do modelo gerado e avaliar seus resultados via determinado método ou teste.

Para a calibração, foram utilizados os dados de $01 / 01 / 2005$ a $31 / 12 / 2009$ e para a verificação os dados de 01/01/2010 a 31/12/2010. Tal definição se deu em função da necessidade de se utilizar um período maior de dados para que o modelo possa ser treinado e, a partir de seu resultado, testado utilizando-se um período menor de dados. Ainda, levou-se em consideração para tal definição, a relação entre o número de ocorrências totais de alagamentos em cada ano e o número de dias com ocorrência para cada ano (Tabela 2). Como o número de dias com ocorrência em cada ano permaneceram muito próximos com exceção do ano de 2007, optou-se então por se utilizar o ano de 2010 para testar o modelo.

Tabela 2 - Relação entre número de ocorrências de alagamentos e de dias com ocorrência de alagamentos

\begin{tabular}{ccccccc}
\hline Anos & $\mathbf{2 0 1 0}$ & $\mathbf{2 0 0 9}$ & $\mathbf{2 0 0 8}$ & $\mathbf{2 0 0 7}$ & $\mathbf{2 0 0 6}$ & $\mathbf{2 0 0 5}$ \\
\hline $\begin{array}{c}\text { Número de } \\
\text { Ocorrências }\end{array}$ & 297 & 492 & 251 & 514 & 522 & 277 \\
\hline $\begin{array}{c}\text { Dias com } \\
\text { Ocorrências }\end{array}$ & 57 & 66 & 47 & 34 & 52 & 47 \\
\hline
\end{tabular}

Fonte: O autor, 2011 
Com tais considerações a cerca de quais períodos deveriam ser utilizados para a calibração e verificação do modelo, utilizou-se a rede SOM, tendo como base o sistema operacional Linux bem como todas as funções para inicialização do SOM, treino e mensuração do erro.

Esta rede tem como um dos resultados os chamados "codebooks" que objetiva a formação de padrões que representem as características de certo momento sendo seu uso baseado na comparação entre um elemento do codebook e o arquivo de entrada através de sua distância euclidiana. Os "codebooks" são traduzidos como os padrões de chuva crítica para ocorrência de alagamentos em Curitiba.

\section{RESULTADOS E DISCUSSÃO}

Como já sabido, o SOM possui como principal característica, ser uma rede que faz o reconhecimento de padrões dentro de uma determinada série de dados. Kohonen (2001) comenta que o reconhecimento de padrões é uma tarefa que aproxima muito as redes neurais dos seres humanos, podendo ser definido como o processo em que um conjunto de entradas ou características (padrão) é atribuído a uma classe entre um conjunto definido de classes. É também chamado de classificação.

A partir da identificação dos padrões de chuva, que são exatamente os ligados a deflagração dos alagamentos em Curitiba, fez-se a associação da probabilidade em que cada padrão ocorre.

Foram analisados os padrões que ocorrem com probabilidades maiores ou iguais a $75 \%$ e probabilidades maiores ou iguais a $50 \%$. Tal definição se deu em função de considerar que os padrões com probabilidades abaixo desses limiares possuem chances mais reduzidas de causarem alagamentos, perturbando a análise dos padrões. Para as probabilidades maiores ou iguais a $75 \%$ e $50 \%$ foram identificados e agrupados dois tipos principais de padrões, os quais se convencionou chamar de "Padrão 1" e "Padrão 2". A Figura 2 a 5 caracterizam em forma de gráfico tais padrões.

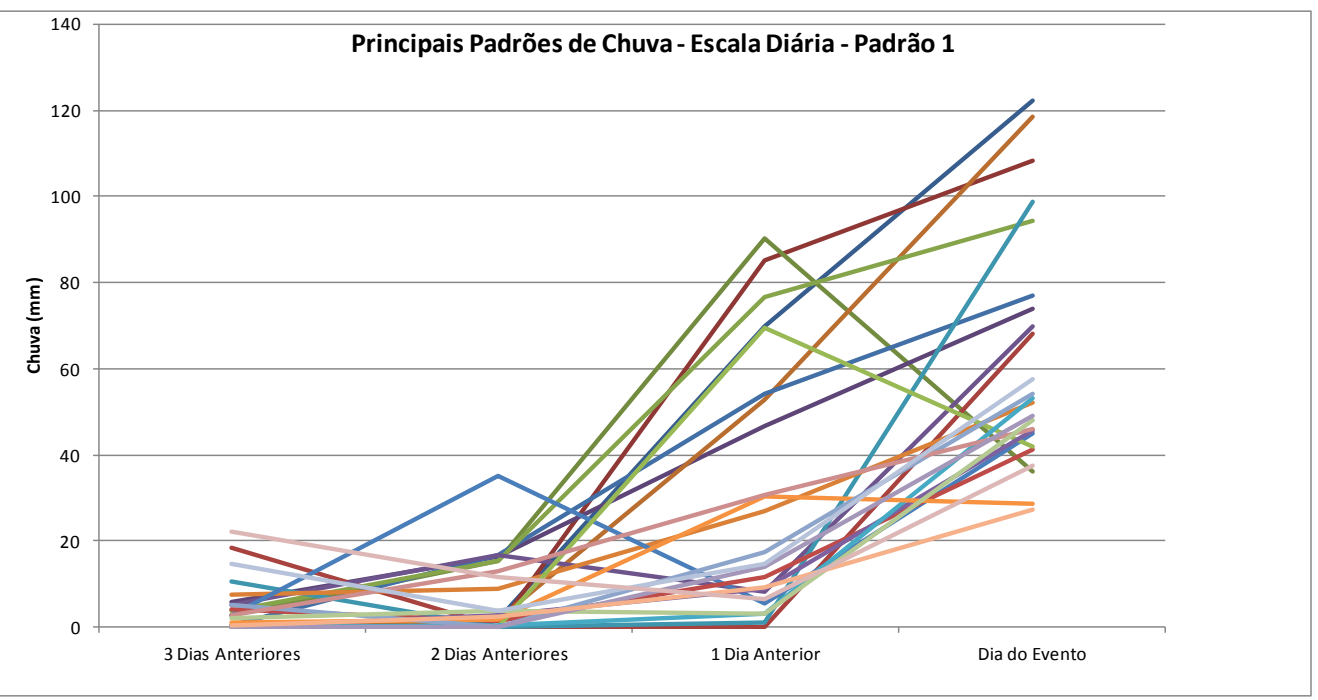

Figura 2 Padrões de chuva do tipo 1 - probabilidades acima de $75 \%$ 


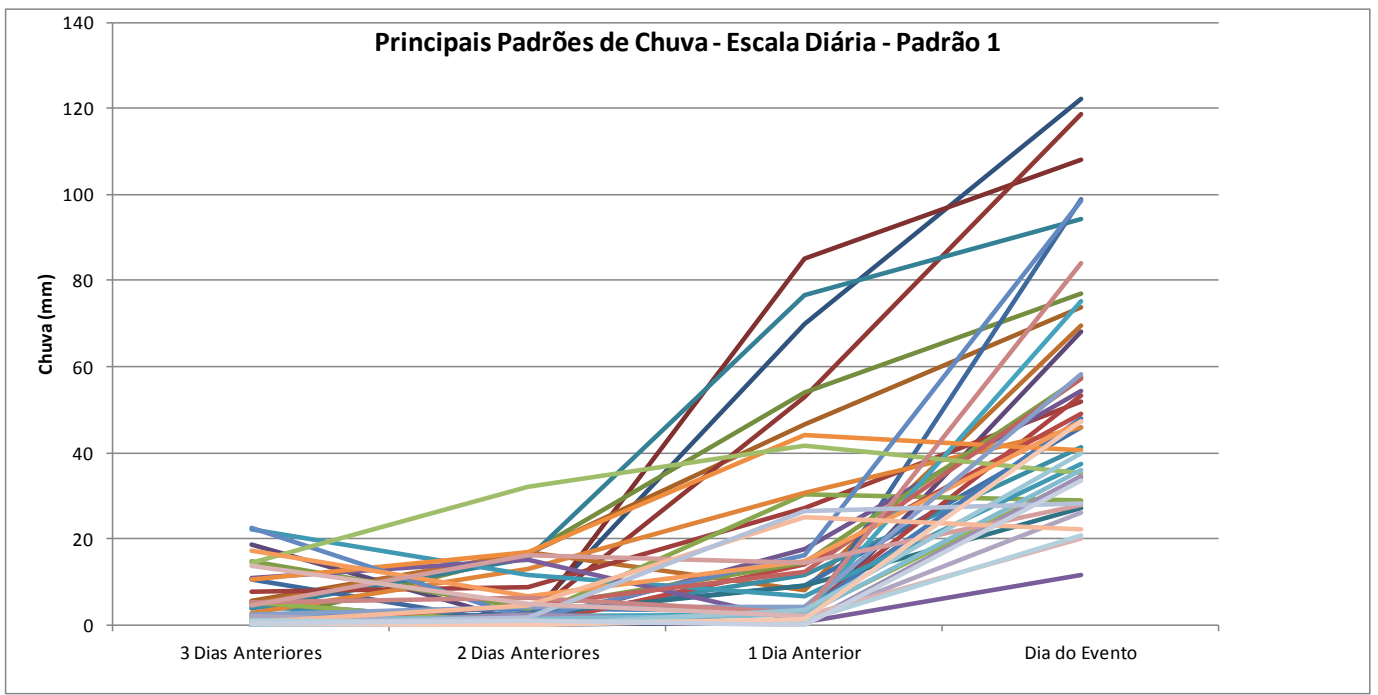

Figura 3 Padrões de chuva do tipo 1 - probabilidades acima de 50\%

Saliente-se que para as análises e apresentações dos resultados referentes aos padrões, a chuva foi acumulada em períodos diários.

A partir da análise dos gráficos (Figura 2 e 3), nota-se que o padrão 1 , tanto para probabilidades maiores ou iguais a $75 \%$ como $50 \%$, está ligado muito mais a dinâmica da chuva que ocorre especificamente no dia do evento do que a chuva que ocorre nos dias anteriores, sendo estas últimas de menor importância na deflagração de um alagamento. No entanto, observa-se que, mesmo com menor importância, têm-se chuvas significativas também no primeiro dia anterior ao do evento.

Com relação a quantidade precipitada no dia do evento levando em consideração as probabilidades maiores ou iguais a $75 \%$ tem-se valores acima de $20 \mathrm{~mm}$ podendo chegar até maior de $100 \mathrm{~mm}$, com média de $62,2 \mathrm{~mm}$. Para 1,2 e 3 dias anteriores, a média de precipitação é de $30,6 \mathrm{~mm}, 7 \mathrm{~mm}$ e 4,5 $\mathrm{mm}$ respectivamente, mostrando novamente a importância da chuva no dia do evento.

Em relação a precipitação que ocorre levando em consideração as probabilidades maiores ou iguais a $50 \%$, a média para o dia do evento é de chuvas em torno de $53,5 \mathrm{~mm}$ e para o primeiro, segundo e terceiro dias anteriores é de $18,5 \mathrm{~mm}, 5,7 \mathrm{~mm}$ e $5,1 \mathrm{~mm}$ respectivamente.

De forma geral, pode-se dizer que o padrão 1 de chuva está intimamente ligado as chuvas convectivas, também chamadas de "chuvas de verão", que ocorrem devido ao aquecimento de massas de ar úmido que estão em contato direto com a superfície quente, sendo caracterizadas pela grande intensidade, curta duração e concentradas em pequenas áreas.

As Figuras 4 e 5 mostram o padrão 2 de chuvas, também para probabilidade maiores ou iguais a 75 e $50 \%$. Pode-se notar que fica bem caracterizada a grande diferença deste padrão quando comparado com o padrão 1, principalmente em função de no dia do evento a quantidade precipitada ser bem menor ou até nula, como no caso do padrão analisado para probabilidade $\geq 75 \%$. Dentre os padrões analisados para probabilidades $\geq 75 \%$ foram encontrados apenas quatro com o mesmo comportamento. Para probabilidades $\geq 50 \%$ o número já foi bem maior, e também mostrando o mesmo comportamento. 


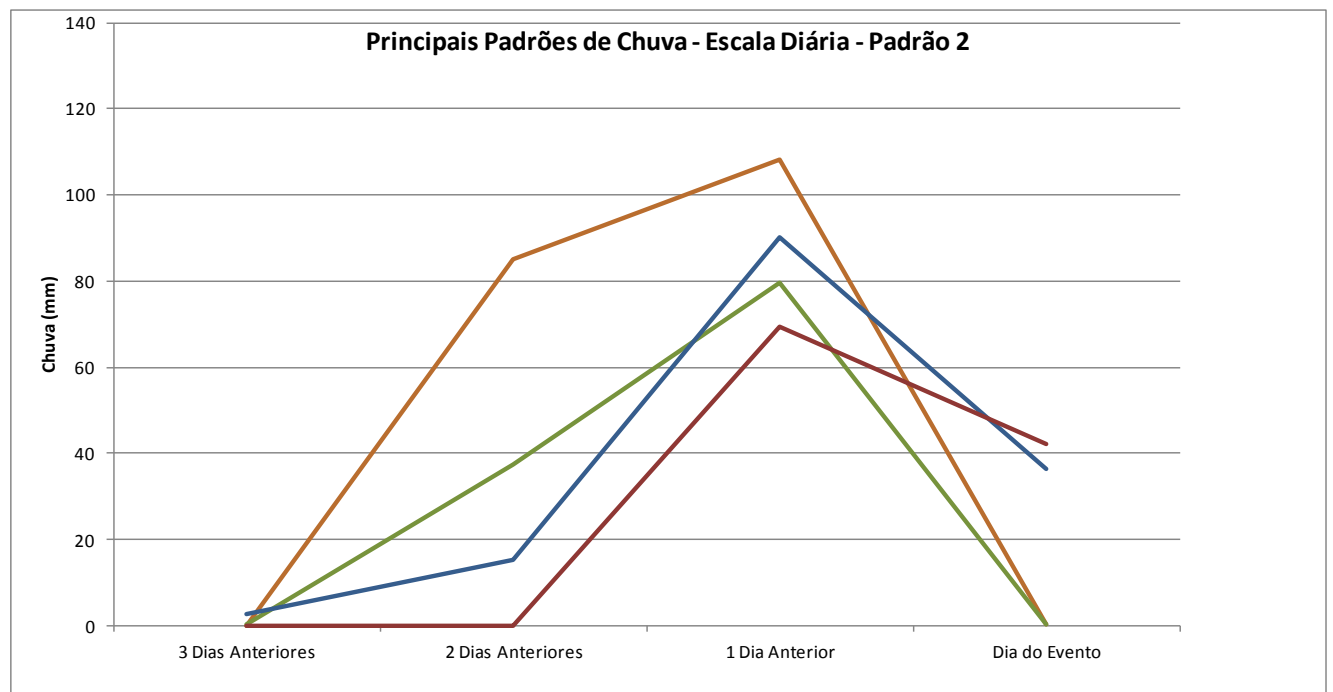

Figura 4 Padrões de chuva do tipo 2 - probabilidades acima de $75 \%$

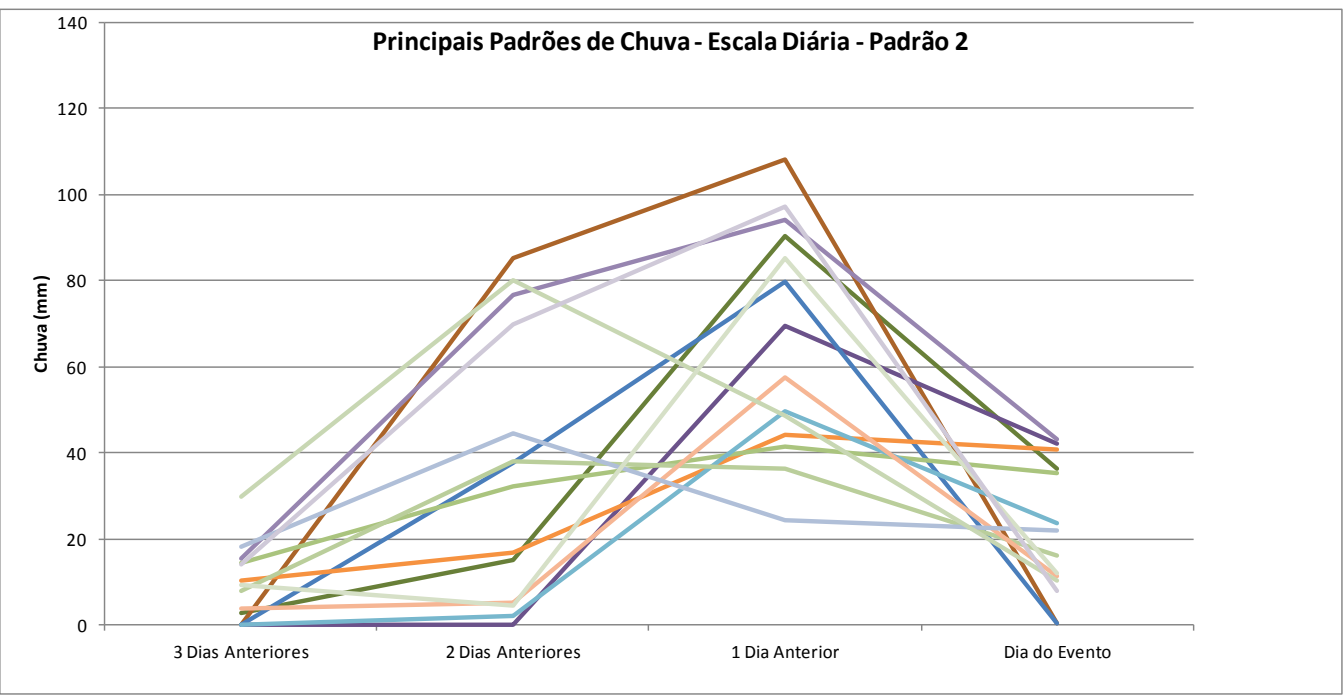

Figura 5 Padrões de chuva do tipo 2 - probabilidades acima de 50\%

Como comentado, os gráficos refletem de maneira clara que a chuva de maior intensidade é aquela ocorrida no dia anterior ao do evento ou até 2 dias anteriores, com quantidade precipitada em torno de $80 \mathrm{~mm}$ até maior que 100 $\mathrm{mm}$ (Figura 4) e que podem variar de maior de $20 \mathrm{~mm}$ a maior de $100 \mathrm{~mm}$ (Figura 5).

A partir de tais dados, infere-se que para deflagrar um alagamento em um dia posterior, tal quantidade de chuva tenha ocorrido durante a noite do dia anterior ou ainda estar associada a chuvas de intensidade média ao longo de todo o dia anterior. Como para os registros de alagamentos analisados têm-se os dados referente ao horário em que o mesmo ocorreu para os anos de 2009 e 2010, considera-se que tal explicação tenha coerência.

Sob outra perspectiva e interpretação, percebe-se que ao longo do segundo e terceiro dias anteriores ao do evento, mesmo que pequeno, há registros de chuva. Quando associado esse montante ao ocorrido no dia anterior ao do evento, demonstra-se que nesse caso os alagamentos se dão 
muito mais em função do acumulado de chuva durante o período do que o ocorrido no dia do evento, ao contrário do padrão 1.

Para este padrão, infere-se que a chuva tenha um comportamento mais ligado a dinâmica das frentes frias, que costumam trazer quantidades significativas de precipitação quando atuam sobre Curitiba. Quando há uma frente estacionária atuando sobre Curitiba, por exemplo, a frente fria deixa de se mover. Se existirem ciclones migrando ao longo dessa frente estacionária, há maior possibilidade das precipitações serem em maior quantidade (vezes e $\mathrm{mm}$ ). Assim, infere-se que o comportamento apresentado pelo padrão 2 esteja ligado a tal dinâmica, ou seja, chuvas regulares ao longo de mais dias.

Comparando em termos de frequência o padrão 1 e 2, verifica-se que o padrão 1 além de ser o mais frequente, também apresentou maiores intensidades máximas de chuva, atingindo índices superiores a $120 \mathrm{~mm}$ acumulados em um dia, com diminuição ao longo dos dias anteriores. O padrão 2 ocorre com menor frequência, no entanto, com intensidades de chuva diária podendo superar $100 \mathrm{~mm}$.

Ressalta-se que a ideia de comparar os padrões de chuva do ponto de vista de sua frequência não segue a linha de raciocínio utilizada para dimensionamento de obras de controle de erosão e hidráulicas (vertedores de barragens, sistemas de drenagem, galerias pluviais, dimensionamento de bueiros) ou ainda para identificar chuvas com maior poder erosivo, em que são calculadas equações de intensidade-duração-frequência (IDF) ou então classificadas em padrão avançado, intermediário e atrasado (HORNER\& JENS, 1941). Neste trabalho, os aspectos ligados a intensidade, duração e frequência são analisados de forma geral, buscando diferenciar e caracterizar os padrões de chuva responsáveis por causar os alagamentos gerados via o SOM.

Ainda com objetivo de caracterizar os padrões, agora principalmente em termos de intensidade e duração, foram elaborados gráficos de área, buscando quantificar a chuva acumulada para o dia correspondente, a partir do cálculo dos percentis para 5, 10, 25, 50, 75, 90, 95 e 100. Um gráfico de área enfatiza a magnitude de alteração ao longo do tempo. Os valores de chuva em milímetros foram exibidos como um conjunto de pontos conectados por uma linha, com uma área preenchida abaixo da linha. Os valores são representados pela altura do ponto medida pelo eixo " $y$ ". Os rótulos de categoria, neste caso os dias, foram exibidos no eixo " $x$ ". Associado a este gráfico optou-se por incluir a mediana

Neste estudo, os gráficos de área mostram em termos de percentagem, qual o limite mínimo e máximo de chuva que está relacionado a um padrão e, portanto, a ocorrência de um evento de alagamento ao longo dos 4 dias analisados.

Analisando a Figura 6 que mostra o gráfico de área para o padrão 1, ou seja, padrões com alta probabilidade de ocorrência (acima de 75\%), pode-se observar novamente que a chuva no dia do evento é primordial para ocorrência dos alagamentos. 


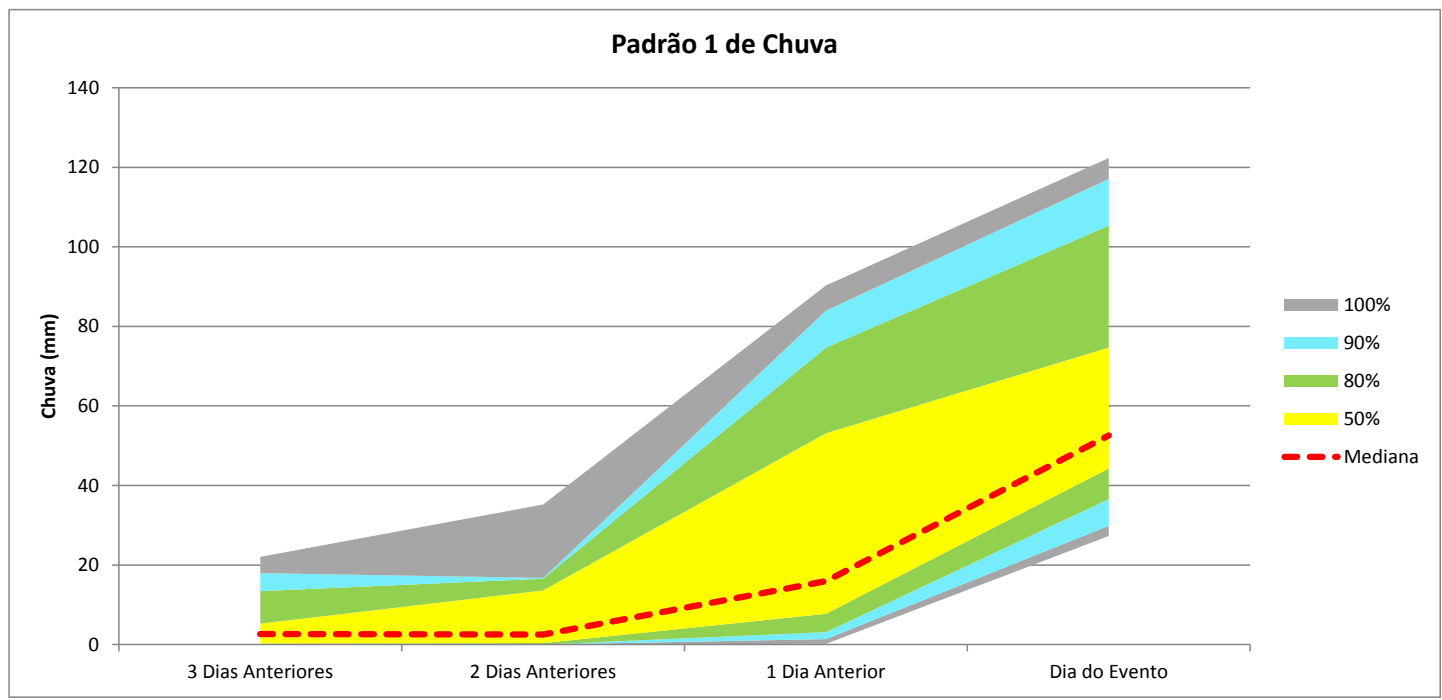

Figura 6 Gráfico de área dos padrões de chuva do tipo 1 - probabilidades acima de $75 \%$

Em 50\% dos casos, o índice pluviométrico teve como mínimo 36 mm/dia e $74 \mathrm{~mm} /$ dia como o máximo, ficando a mediana em $52 \mathrm{~mm} /$ dia. Levando em conta $80 \%$ dos casos analisados, para padrões de probabilidades maiores de $75 \%$, o índice pluviométrico mínimo e máximo ficou entre 29 e 105 mm/dia respectivamente.

No dia anterior ao do evento, em $50 \%$ dos casos os valores de chuva variaram entre 3 e $53 \mathrm{~mm}$ para o mínimo e máximo, com mediana de $15 \mathrm{~mm}$. Analisando $80 \%$ dos casos, tais índices tiveram variação entre 1 e $74 \mathrm{~mm} /$ dia. Pode-se perceber ainda que no segundo e terceiro dias anteriores, a chuva já torna-se de menor relevância, com mediana próxima de $0 \mathrm{~mm} / \mathrm{dia}$.

Com tais resultados e interpretações, pode-se afirmar que para que se tenha grande probabilidade de ocorrência de evento de alagamento em Curitiba (56\%), deve-se ter chuva acumulada em torno de $36 \mathrm{~mm}$ no dia do evento.

Sob outra perspectiva e ainda levando em conta as áreas representadas no gráfico, avalia-se que a relação entre os dias e a quantidade de chuva precipitada é crescente ao longo dos 4 dias, mostrada pela maior inclinação das curvas e também da mediana, traduzindo sempre tendência positiva e comprovando que o dia do evento possui maior relevância.

Quando analisado o padrão 1 com probabilidade maiores ou iguais a $50 \%$ (Figura 7), verifica-se que a tendência positiva apresentada no gráfico anterior se mantêm, visto que a curva representando a mediana possui praticamente a mesma inclinação da apresentada anteriormente. 


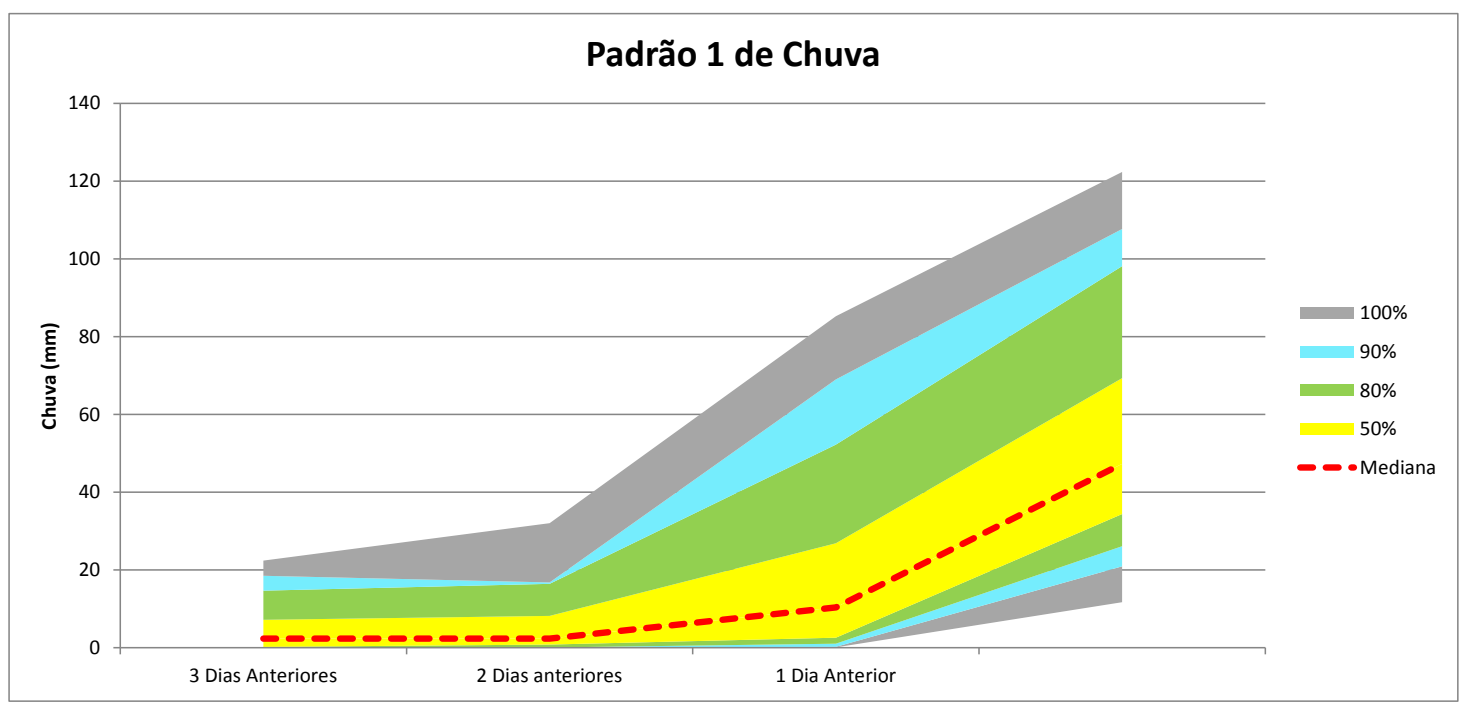

Figura 7 Gráfico de área dos padrões de chuva do tipo 1 - probabilidades acima de $50 \%$

No entanto, enquanto a mediana tinha como valor $52 \mathrm{~mm}$ no dia do evento para probabilidades maiores ou iguais a $75 \%$, agora é de $41 \mathrm{~mm}$, com índices de 11 e $57 \mathrm{~mm}$ para o mínimo e máximo respectivamente, mostrando diminuição dos valores em função da maior quantidade de dados analisados. De qualquer forma, ainda fica evidente que a chuva no dia do evento é primordial para ocorrência dos alagamentos.

As Figuras 8 e 9 apresentam os gráficos de área para o padrão 2 de chuva, para probabilidades maiores ou iguais a 75 e $50 \%$ respectivamente.

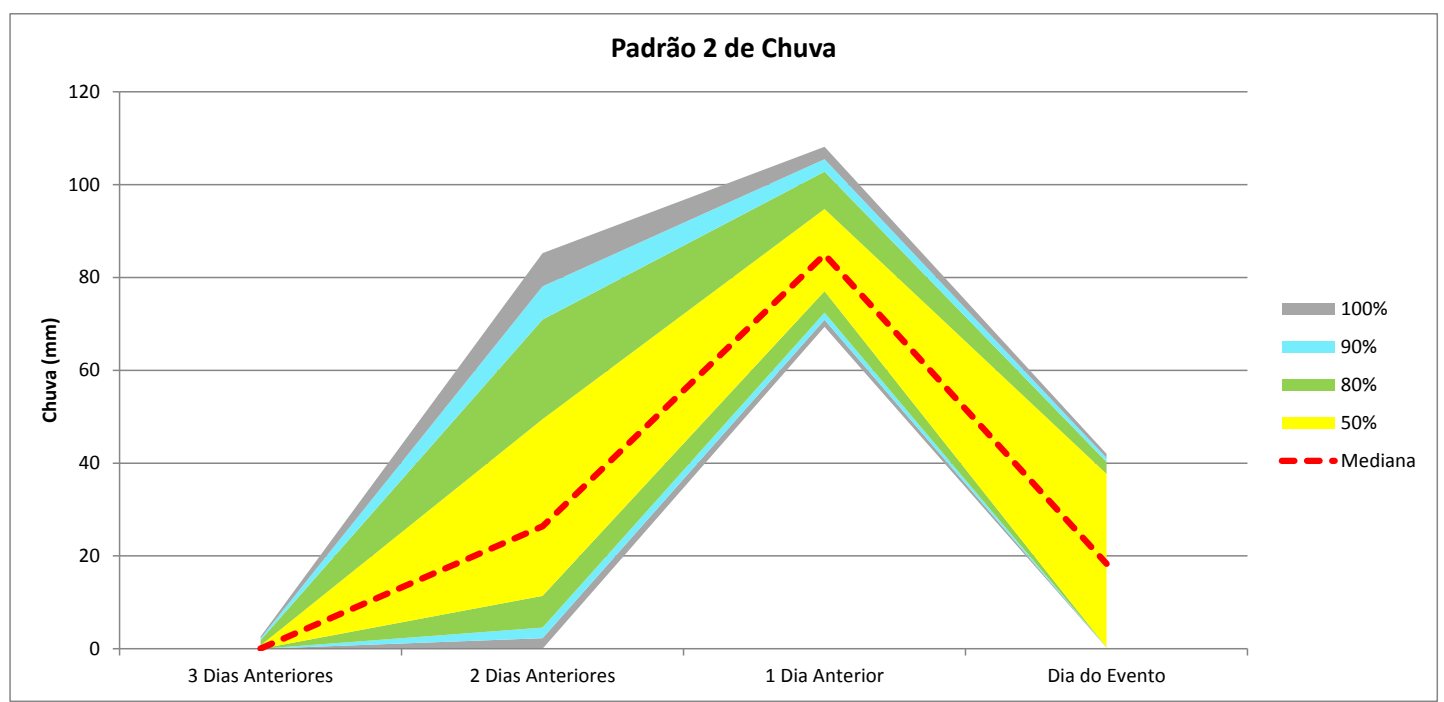

Figura 8 Gráfico de área dos padrões de chuva do tipo 2 - probabilidades acima de $75 \%$ 


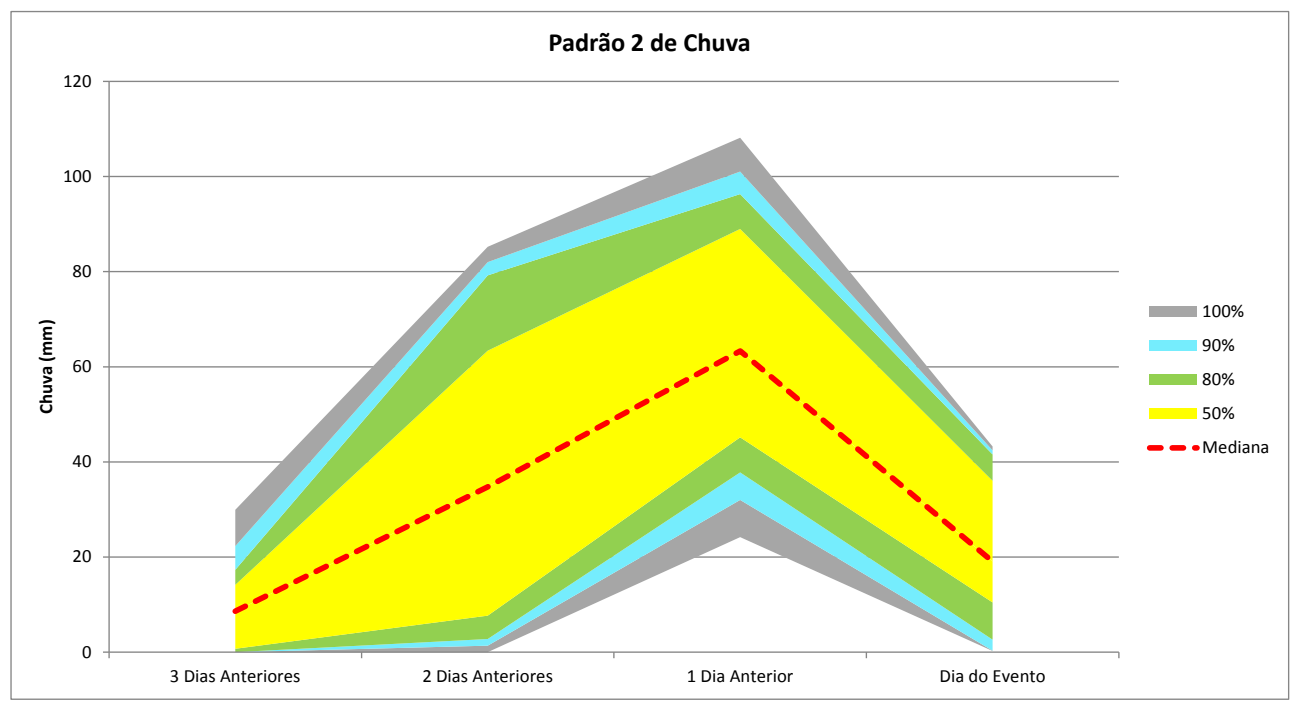

Figura 9 Gráfico de área dos padrões de chuva do tipo 2 - probabilidades acima de $50 \%$

Corroborando o que já foi discutido, os gráficos traduzem a importância da chuva no dia anterior ao do evento. Na Figura 8, em função de serem utilizadas apenas 4 curvas (rever Figura 3 ) para geração do gráfico, nota-se um comportamento em que praticamente em todos os casos a chuva no dia anterior teve índices pluviométricos superiores a $70 \mathrm{~mm}$, demonstrando que este índice é o responsável por deflagrar alagamentos no próximo dia. A mediana foi de $84 \mathrm{~mm}$ de chuva. No dia do evento, ao contrário, a mediana foi de $18 \mathrm{~mm}$.

O gráfico da Figura 9 ilustra a mesma dinâmica já descrita acima. No entanto em função da maior quantidade de curvas (rever Figura 5) utilizadas para gerar o gráfico, verifica-se um comportamento que possa representar de melhor forma este padrão. Com relação aos índices pluviométricos, constata-se que em $50 \%$ dos casos o mínimo ficou acima de $10 \mathrm{~mm}$ e o máximo acima de $85 \mathrm{~mm}$ para o dia anterior ao do evento. A mediana foi de $53 \mathrm{~mm}$. No dia do evento, a mediana foi de $22 \mathrm{~mm}$, sendo o mínimo de 4 e o máximo de $37 \mathrm{~mm}$.

Sintetizando os resultados para o padrão 2 de chuva, pode-se afirmar que as curvas apresentam tendência de crescimento a partir do terceiro dia até o primeiro dia anterior ao do evento, sendo que especificamente no dia do evento, os índices pluviométricos podem ser até de zero, mas podendo atingir $40 \mathrm{~mm}$. Ainda, verifica-se que tanto no terceiro quanto no segundo dias anteriores ao do evento existe registros de chuva mostrando novamente que a dinâmica dos alagamentos quando considerado este padrão se dá em virtude do acumulado de chuva no período e não em função de chuvas torrenciais em um dia apenas.

Como afirmado no início da discussão deste item, todos os resultados foram gerados observando-se a chuva acumulada diária. Apenas a título de curiosidade, apresenta-se na Figura 10 uma análise com a chuva acumulada a cada 6 horas para todos os padrões com probabilidades maiores ou iguais a $75 \%$.

A partir do gráfico de área, constata-se que realmente os alagamentos se originam com maior frequência a partir da chuva ocorrida no dia do evento, principalmente a chuva ocorrida nas últimas $12 \mathrm{~h}$. Nota-se que podem ser identificados dois picos em que a chuva é mais significativa, variando em " $A$ " de 5 a $38 \mathrm{~mm} / 6 \mathrm{~h}$ e em "B" de 0 a $20 \mathrm{~mm} / 6 \mathrm{~h}$ para os limites mínimos e máximos 
respectivamente e para $50 \%$ dos casos (cor amarela). Os valores para a mediana e " $A$ " e " $B$ " são de 18 e 7 mm/6h respectivamente.

Considerando estes dois picos, pode-se fazer referência aos dois tipos de padrões discutidos anteriormente e verificar em quais horas do dia as chuvas são mais significativas, sendo que para o padrão 1 são as últimas 12 horas e para o padrão 2 também as últimas 12 horas do dia anterior, mostrando novamente que possivelmente a chuva que deflagra alagamentos considerando o padrão 2 é a que ocorre principalmente na noite anterior ao dia do evento.

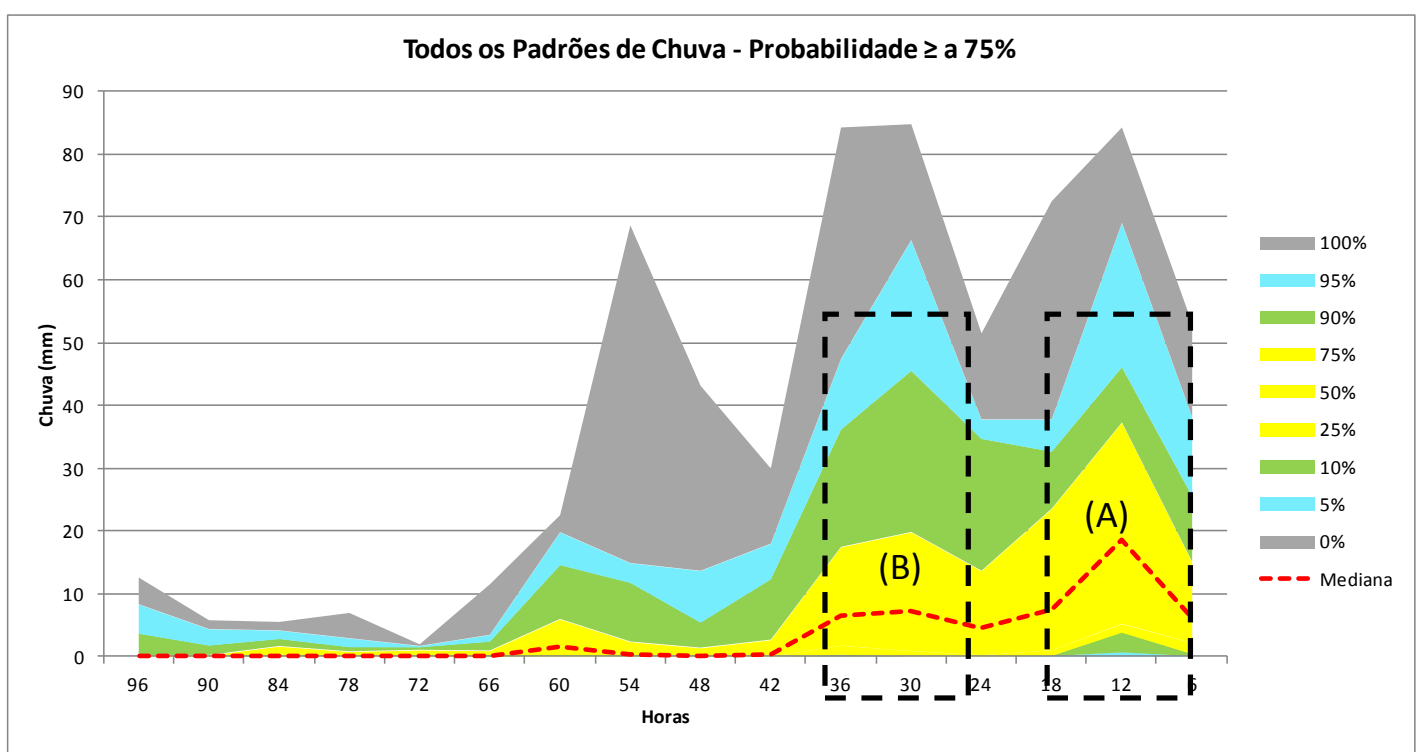

Figura 10 Gráfico de área para todos os padrões de chuva considerando as probabilidades maiores ou iguais a $75 \%$ - Escala de 6 horas

Pode-se ainda caracterizar a partir da inclinação das curvas, a tendência crescente para o índice pluviométrico ao longo de 6 em 6 horas, com pico nas últimas 12 horas.

Ainda com a intenção de caracterizar os padrões de chuva, mas pensando especificamente na frequência em que cada um desses padrões ocorre, foram elaborados gráficos de frequência acumulada, considerando o acumulado diário para os 4 dias e probabilidades $\geq$ a $75 \%$, $\geq$ a $50 \%$, $\leq$ a $50 \%$ e $\leq$ a $25 \%$.

A partir da análise dos gráficos de frequência acumulada representados na Figura 11, fica evidente que os padrões associados a altas probabilidades ( $\geq$ a $75 \%$ e $\geq$ a $50 \%$ ) são bem diferentes dos padrões associados a baixas probabilidades ( $\leq$ a $50 \%$ e $\leq$ a $25 \%$.) mostrando que a chuva no dia do evento é primordial para ocorrência dos alagamentos. 

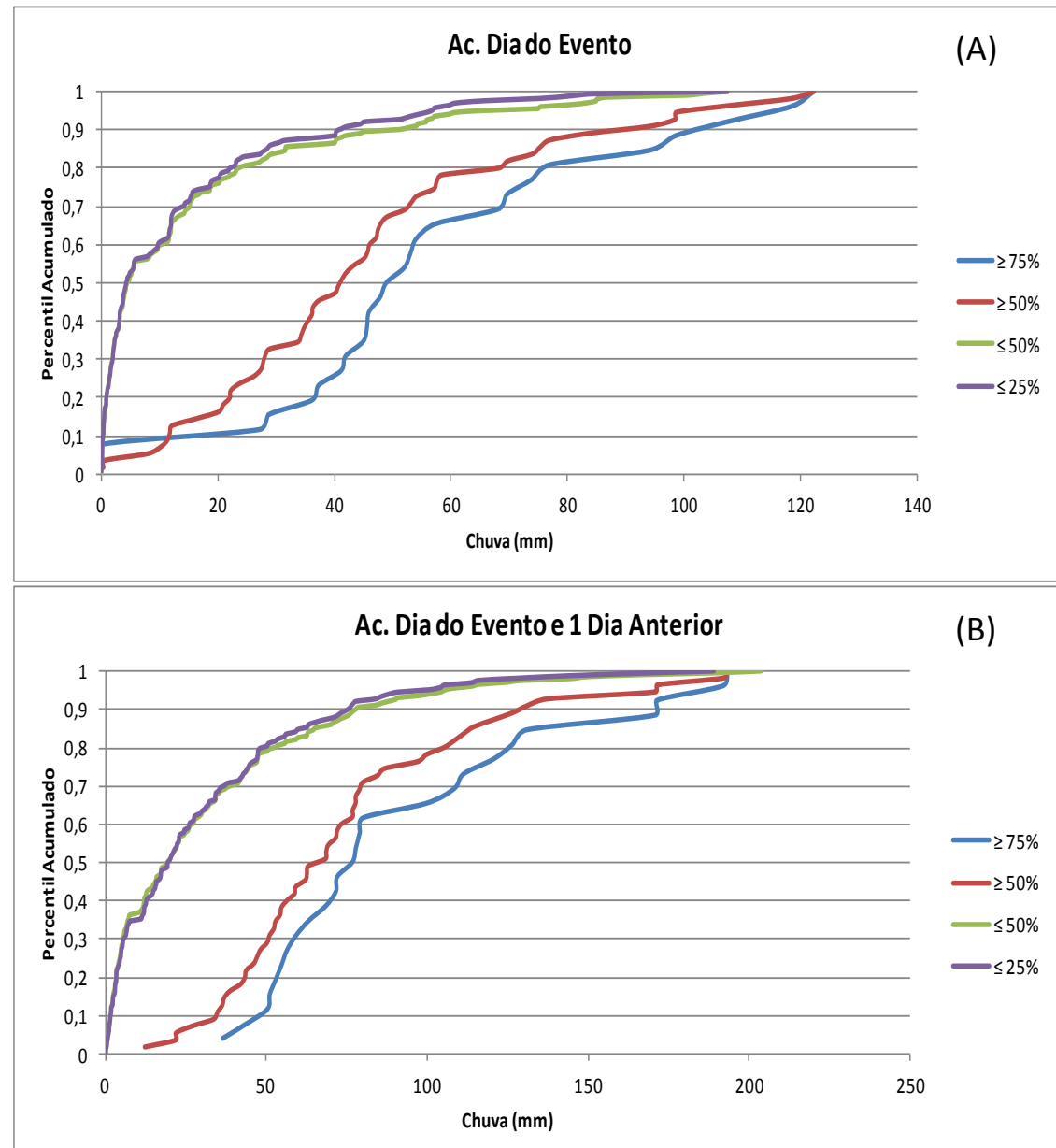

Ac. Dia do Evento e 2 Dias Anteriores

(C)

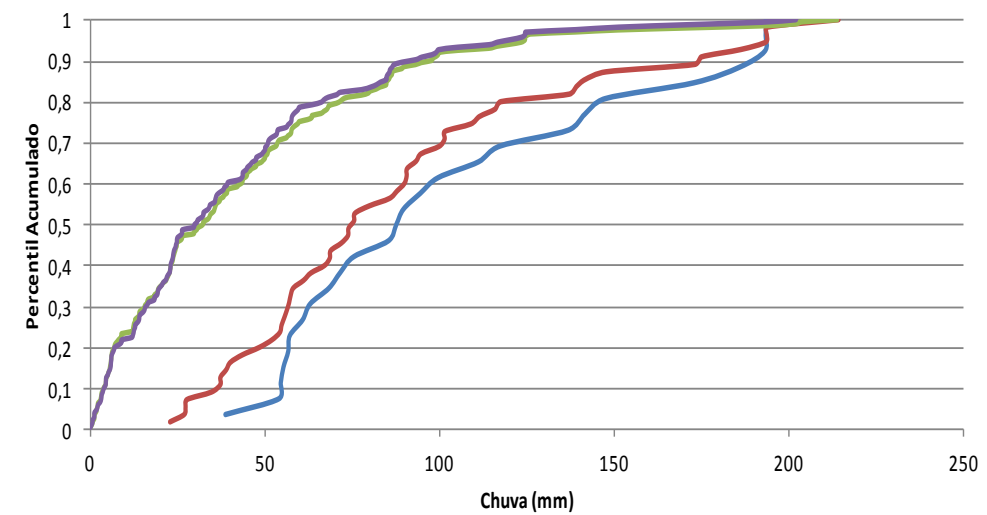

$$
\begin{array}{r}
\longrightarrow \geq 75 \% \\
-\geq 50 \% \\
-\leq 50 \% \\
\longrightarrow \leq 25 \%
\end{array}
$$




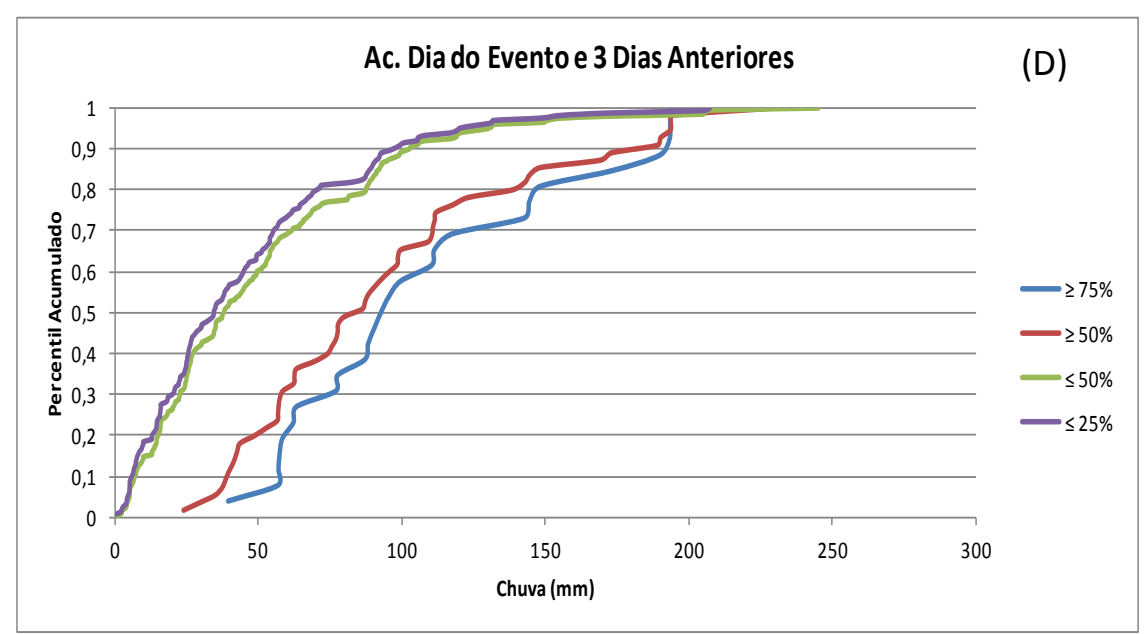

Figura 11 Gráfico de frequência da chuva acumulada no dia do evento, no dia do evento e 1 dia anterior, no dia do evento e 2 dias anteriores e no dia do evento e 3 dias anteriores, para probabilidades $\geq 75 \%, \geq 50 \%$, $\leq 50 \%$ e $\leq 25 \%$

Interpretando os gráficos, pode-se ainda dizer que os padrões associados a altas probabilidades de ocorrência realmente estão relacionados a processos de alagamentos e não de inundações, pois se estivessem ligados a inundações, a importância da chuva acumulada nos 4 dias teria maior relevância, ou seja, nos gráficos "C" e "D", as curvas deveriam estar mais afastadas entre si e não com tendência de aproximação, mostrando que a chuva acumulada para 4 dias contribui, mas a de maior importância é a ocorrida no dia do evento. Tal fato fica evidente quando observa-se o gráfico "A", em que as curvas estão afastadas uma da outra, ilustrando a importância da chuva no dia do evento.

No gráfico " $A$ ", observa-se que há alta frequência de chuvas com menos de $20 \mathrm{~mm}$ e que estão associadas a baixas probabilidade de ocorrência, ou seja, $\leq$ a $50 \%$ e $\leq$ a $25 \%$. O contrário também pode ser observado, pois para probabilidades $\geq$ a $75 \%$ e $\geq$ a $50 \%$ têm-se baixas frequências para chuvas em torno de $20 \mathrm{~mm}$ e maiores frequências para chuvas entre 30 e $70 \mathrm{~mm}$ corroborando o que já foi discutido nos gráficos de área sobre a quantidade de chuva necessária para deflagrar os alagamentos.

Ainda sobre o gráfico "A", verifica-se que as duas curvas ligadas a baixas probabilidades de ocorrência de alagamento estão muito próximas, mostrando que não há diferenças significativas na precipitação que ocorre associada a estas probabilidades, diferentemente das curvas de 50 e $75 \%$ que já mostram alguma diferença.

Sendo assim, através de tais análises e das discussões apresentadas neste item, mostrou-se as principais diferenças em relação aos padrões de chuva definidos, bem como aspectos ligados a intensidade, duração e frequência.

Para concluir, sabe-se que os alagamentos se dão em função de um determinado padrão de chuva como já discutido, no entanto, há outros fatores que contribuem para sua ocorrência, como por exemplo, a questão já intrínseca das metrópoles (como Curitiba), referentes às grandes áreas pavimentadas e impermeáveis. Sabe-se que o processo de urbanização causa mudanças no 
microclima das cidades. O intenso processo de desmatamento e a construção de residências, edifícios, indústrias, ocupação das áreas de várzeas e a impermeabilização do solo com asfalto acarretam no aumento de temperatura dos centros urbanos em relação às áreas periféricas (afastadas do centro) e às áreas rurais.

Além do desmatamento e da impermeabilização do solo, o consumo de combustíveis fósseis por automóveis e indústrias torna a cidade uma fonte de calor, fenômeno conhecido como "ilha de calor". O aumento de temperatura nos centros urbanos intensifica a evaporação; além disso, o material particulado (poluentes) em suspensão favorece a formação de núcleos de condensação na atmosfera. O resultado é o aumento da quantidade de chuvas.

Drew (1986) já mostrava que em áreas alteradas pela urbanização a quantidade de chuva anual é $5 \%$ maior e, em dias de chuva, a precipitação (quantidade de chuva medida) é $10 \%$ superior se comparada com as áreas rurais.

Aliado a esses fatores, tem-se a questão ligada a quantidade de lixo presente na cidade. O lixo acaba entupindo os bueiros e sendo carregado para as galerias pluviais e córregos que atravessam as áreas urbanas. Com isso, é diminuída a capacidade de recebimento e escoamento da água proveniente da cidade e por consequência, aumentada as chances de ocorrência dos alagamentos.

A prefeitura municipal via secretaria de obras e de meio ambiente, faz um trabalho de manutenção permanente dos bueiros e galerias em Curitiba, no entanto a prioridade é a áreas central, ficando os bairros em direção a periferia descobertos de tal serviço, sendo comum apenas a visita quando há reclamação ou solicitação de limpeza.

De acordo com matéria publicada pela mídia impressa de Curitiba, é realizada a limpeza manual e também com a presença de um caminhão especial, mas como são inúmeros bueiros, fica praticamente inviável atender todos. Neste caso, os entupidos, acabam se tornando os grandes "vilões" em dias de chuva forte.

Vale lembrar que os alagamentos resultam por si só em impactos socioeconômicos. Quando associados a outros problemas tais como a falta de saneamento básico, a pobreza da população e a ocupação de áreas ribeirinhas, tende a gerar novos agravantes entre eles prejuízo com bens materiais (carros, motos, casas entre outros), interrupção de serviços básicos (energia elétrica, abastecimento de água, transporte público), problemas de saúde pública e até mesmo a perda de vidas.

\section{CONSIDERAÇÕES FINAIS}

A utilização de inteligência artificial, especificamente a rede SOM, é um método alternativo de modelagem de processos relacionados não só ao ambiente natural, mas também relacionado a outras ciências como a medicina, informática, administração entre outras, tendo como grande vantagem a possibilidade de modelar processos não-lineares de forma implícita. No entanto, a maior limitação encontra-se no tamanho da amostra utilizada para o treinamento e aprendizagem da rede. Acredita-se que para este estudo, os resultados poderiam ser melhorados com uma amostra maior, ou seja, um maior número de dados de estimativa de chuva e também de alagamentos. No 
entanto, foram utilizados os dados de 2005 a 2010, disponíveis para o momento.

Outra vantagem da rede SOM é justamente a sua capacidade de identificação de padrões. Neste sentido, este trabalho possui caráter de inovação e pioneirismo. Inovação, pois foram identificados via rede neural os principais padrões de chuva que deflagram os alagamentos em Curitiba e, pioneirismo em função da não identificação na literatura consultada de trabalhos que demonstrem a relação da chuva e ocorrência de alagamentos via rede de Kohonen.

Em relação aos padrões de chuva, foram identificados dois padrões principais que deflagram os alagamentos. A partir dos gráficos de linha e de área elaborados para caracterizar o padrão 1 de chuva, mostrou-se que para a ocorrência de um alagamento deve necessariamente ser registrada chuva no dia do evento, sendo a mesma superior ou igual a $36 \mathrm{~mm}$ no dia do evento. Infere-se, portanto que este padrão esteja ligado as chuvas convectivas que ocorrem principalmente no período de verão.

O padrão 2 apresentou características diferentes sendo que o maior índice de precipitação foi identificado para o dia anterior ao do evento mas com valores crescentes de precipitação já a partir do terceiro dia anterior ao do evento. Desta forma, infere-se que tal padrão tenha dinâmica relacionada a entrada de frentes frias, que trazem quantidades significativas de precipitação podendo atuar por diversos dias sobre determinada área.

De forma geral, quando comparados os dois padrões, o padrão 1 apresenta maior frequência e índices pluviométricos podendo ultrapassar os $120 \mathrm{~mm}$ acumulados diários. Mesmo com menor frequência, o padrão 2, de acordo com o investigado no trabalho, pode atingir até $100 \mathrm{~mm}$ acumulados diários.

\section{REFERÊNCIAS BIBLIOGRÁFICAS}

BeNETI, C. A. A.; CALVETTI, L.; PEREIRA FILHO, A. J. Estimativa da Precipitação por Radar e Pluviômetros na Região Metropolitana de Curitiba - Resultados Preliminares. In: Congresso Brasileiro de Meteorologia, 11., 2002, Foz do Iguaçu. CD-ROM.

BENETI, C. A. A.; CALVETTI, L.; PSCHEIDT, I. PEREIRA FILHO, A.J. Avaliação de estimativas de precipitação por satélite utilizando dados de estações de superfícies e radar meteorológico: verificação preliminar no Paraná. In: Anais do XIV Congresso Brasileiro de Meteorologia, Florianópolis-SC, Ago. 2006.

CALVETTI, L.; BENETI, C.; PEREIRA FILHO, A. J. Integração do radar meteorológico dopller do Simepar e uma rede pluviométrica para a estimativa da precipitação. In: SIMPÓSIO BRASILEIRO DE SENSORIAMENTO REMOTO, 11. 2003, Belo Horizonte. CDROM.

CALVETTI, L; BENETI, C.; GONÇALVES, J. E.; MOREIRA, I.; DUQUIA, C.; BREDA, A. e ALVES, T. A. (2006). Definição de Classes de Precipitação para utilização em Previsões por Categoria e Hidrológica. In Anais do XIV Congresso Brasileiro de Meteorologia, Florianópolis-SC, Ago. 2006.

CALVETTI, L.; BENETI, C.; PSCHEIDT, I.; STRINGARI, D. e PEREIRA FILHO, A. J. Integração de Estimativas de Precipitação por Radar, Satélite e Pluviômetros: Análise 
Espacial para o Paraná. In Anais do XVII Simpósio Brasileiro de Recursos Hídricos. São Paulo - SP, Nov. 2007.

CANALI, N. MURATORI,A.M. Síntese da evolução geomorfológica da bacia de Sedimentação de Curitiba. In: 30 Simpósio Regional de Geologia. Curitiba. Sociedade Brasileira de Geologia. Núcleo de São Paulo; novembro, 1981, Atas, vol.2, 389p

DREW, D. Processos Interativos Homem-Meio Ambiente. 4a ed. São Paulo: Bertrand Brasil, 1998.

FREEMANN, J. A.; SKAPURA, D. M. Neural networks, Algorithms, Applications, and Programming Techniques. New York: Addison Welsley, 1991.

FENDRICH, R. Histórico de acidentes hidrológicos em Curitiba. Bacia Hidrográfica do rio Belém. In: LIMA, R. E. Uso dos solos e dos rios: conceitos e aplicações para a região de Curitiba. Curitiba:UFPR - NIMAD. 2000. 149p.

FORTUNATO, R. A. Subsídios à prevenção e controle das inundações urbanas: bacia hidrográficas do rio Belém, município de Curitiba - PR. Curitiba, 2006. 237 f. Dissertação (Programa de Pós-Graduação em Construção Civil) - Universidade Federal do Paraná.

HAYKIN, S. Redes Neurais: princípios e prática. Trad. Paulo Martins Engel. 2.ed. Porto Alegre: Bookman, 2001.

JICA. Japan International Cooperation Agency. The master plan study on the utilization of water resources in Panará state in the Federative Republic of Brazil. Volume $\mathrm{H}$ - Flood control. 1995. 99 p.

KOHONEN, T. Self-Organizing Maps. 3 ed. Berlim: Springer-Verlag. 2001

LUDWIG JR O. \& MONTGOMERY E. Redes Neurais. Fundamentos e Aplicações com Programas em C. Rio de Janeiro: Ed. Ciência Moderna LTDA, 2007.

PEREIRA FILHO, A. J., K. C. Crawford e Hartzell, C. Statistical Objective Analysis Scheme (SOAS) for Improving WSR-88D Rainfall Estimates. Vol.1: Comparative Analysis Between Stage III and the SOAS over WSR-88D Overlapping Areas. Report R-96-08, 58 pp, Bureau of Reclamation, U.S. Department of Interior. 1996:

PEREIRA FILHO, A., NAKAYAMA, P. T. e NEGRI, A. Gauge, radar and satellite areal rainfal estimates. Sixth International Symposium Hydrological Applications of Weather Radar. Melbourne, Austrália. 2004:

ZANELA, E. O impacto das precipitações, as inundações e a percepção das comunidades atingidas, da imprensa e dos gestores públicos: um estudo de caso no bairro Cajuri Curitiba - PR. Curitiba, 2005. 209 p. Tese (Programa de Doutorado em Meio Ambiente e Desenvolvimento) - Universidade Federal do Paraná.

Texto submetido à RBClima na data de 18/06/2015 